HETEROCYCLES, Vol. 84, No. 1, 2012, pp. 115 - 134. @ 2012 The Japan Institute of Heterocyclic Chemistry
Received, 15th June, 2011, Accepted, 15th July, 2011, Published online, 28th July, 2011

DOI: 10.3987/REV-11-SR(P)3

\title{
PRACTICALLY USABLE C3 BUILDING BLOCKS FOR THE SYNTHESES OF NITRO HETEROCYCLES
}

\section{Nagatoshi Nishiwaki,* Shotaro Hirao, Jun Sawayama, and Kazuhiko Saigo}

School of Environmental Science and Engineering, Kochi University of Technology, Tosayamada, Kami, Kochi 782-8502, Japan

\begin{abstract}
Nitromalonaldehyde (NMA-H) is one of useful synthons for synthesizing nitro compounds. However, NMA-H itself cannot be practically employed because of its unstable property. Therefore, sodium salt of NMA-H (NMA-Na) has been used as its synthetic equivalent from old time, and NMA-Na is still important even now albeit several restrictions with regard to safety and treatability. On the other hand, dinitropyridone, nitropyrimidinone and dinitropyrazole can be employed in place of NMA-Na for the same purpose, and furthermore azadienamines, formylnitroenamines and dinitropyrazole also serve as the synthetic equivalents of NMA-H, which are usable in common organic solvents with safety. These reagents condense with dinucleophiles to afford various kinds of nitro compounds.
\end{abstract}

\section{INTRODUCTION}

A nitro group is one of useful functional groups because of a strong electron-withdrawing ability and its diverse chemical behaviors. ${ }^{1}$ A nitro group considerably decreases the electron density of its scaffold framework by both inductive and resonance electron-withdrawing effects to facilitate reactions with nucleophiles. The $\alpha$-hydrogen of a nitro group becomes highly acidic to form a stable nitronate anion, which reacts with both electrophilic and nucleophilic reagents. Furthermore, a nitro group assists the cleavage of an adjacent carbon-carbon bond, and transforms to versatile functional groups by the Nef reaction or by reduction. Although nitration is a direct method for introducing a nitro group, harsh conditions are sometimes necessary, in which a reactive functional group cannot tolerate. As a supplementary method, a built-in method is employed; a building block possessing a nitro group is condensed with proper reagents to afford nitro compounds, which are not easily available by nitration. 


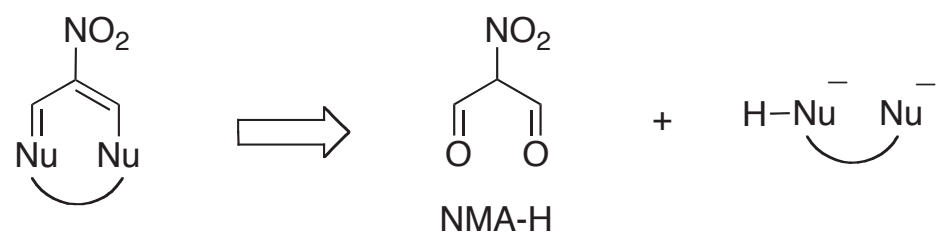

Scheme 1. Nitromalonaldehyde (NMA-H) as a synthon

Indeed, such building blocks often appear as synthons in retrosyntheses, among which nitromalonaldehyde (NMA-H) is an important compound (Scheme 1). NMA-H is a simple compound for a theoretical study on an intramolecular hydrogen bond, proton transfer and quasi-aromaticity. ${ }^{2,3}$ However, NMA-H is too unstable in aqueous solutions to be isolated, presumably due to easily occurring hydrolysis accompanied by a C-C bond fission. ${ }^{4}$ Thus, NMA-H is prepared only by bubbling dry hydrogen chloride to a suspension of sodium nitromalonaldehyde (NMA-Na) in dry carbon tetrachloride. ${ }^{3}$ Hence, it is one of important subjects to develop the synthetic equivalents of NMA-H. From this viewpoint, NMA-Na has been employed for the construction of nitro compounds from old time, which was well reviewed by Fanta and Stein. ${ }^{5}$

\section{SODIUM NITROMALONALDEHYDE (NMA-Na)}

\section{1-1. Preparation of NMA-Na}

The preparation of NMA- $\mathrm{Na}^{6}$ is achieved by treating mucobromic acid (3) which is easily available from furan-2-carboxylic acid $(\mathbf{1})^{7}$ or furfural $(\mathbf{2})^{8}$ by the ring-opening reaction with bromine. However, these methods include somewhat troublesome manipulations, and a small quantity of hydrogen cyanide is evolved in each reaction. ${ }^{9}$
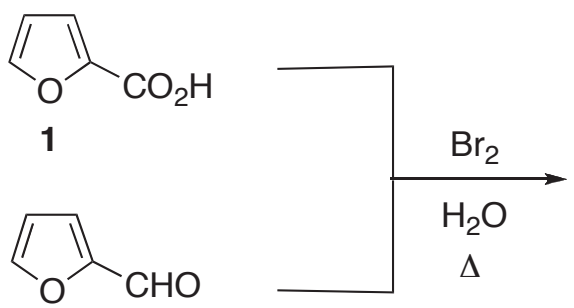<smiles>O=CC(Br)=C(Br)C(=O)O</smiles><smiles>CCO[N+](=O)[O-]</smiles><smiles>CN(C)C(C=O)C(=O)[N+](=O)[O-]</smiles>

Scheme 2. Synthetic routes to NMA-Na via mucobromic acid (3) 


\section{1-2. Syntheses of 2,6-disubstituted 4-nitrophenols}

In a industrial process, substituted nitrophenols are often prepared by the Friedel-Crafts alkylation of phenols followed by nitration, ${ }^{10}$ which includes several restrictions to be overcome. In electrophilic substitutions, the control of regioselectivity is especially a significant problem; it is difficult to prepare successively trisubstituted benzenes. In addition to this problem, an aryl group nor an alkyl chain longer than an ethyl group cannot be introduced by the Friedel-Crafts reaction, and polyalkylation is another problem.

Table 1. Condensation of NMA-Na with various ketones<smiles>O=CC(C=O)[N+](=O)[O-]</smiles>

NMA-Na<smiles>[R]CC(=O)CC</smiles><smiles>C=CC</smiles>

4<smiles>[R]c1cc([N+](=O)[O-])cc([R])c1O</smiles>

5

\begin{tabular}{cccccccc}
\hline $\mathrm{R}^{1}$ & $\mathrm{R}^{2}$ & & yield/\% & $\mathrm{R}^{1}$ & $\mathrm{R}^{2}$ & \multicolumn{2}{c}{ yield/\% } \\
\hline $\mathrm{H}$ & $\mathrm{H}$ & $\mathbf{a}^{\mathrm{a}}$ & $73^{11}$ & $p-\mathrm{ClC}_{6} \mathrm{H}_{4}$ & $\mathrm{H}$ & $\mathbf{l}$ & $62^{14}$ \\
$\mathrm{Me}$ & $\mathrm{H}$ & $\mathbf{b}$ & $88^{5}$ & $\mathrm{Ph}$ & $\mathrm{Et}$ & $\mathbf{m}$ & $72^{12}$ \\
$\mathrm{Et}$ & $\mathrm{H}$ & $\mathbf{c}$ & $70^{5}$ & $\mathrm{Ph}$ & $\mathrm{Ph}$ & $\mathbf{n}$ & $95^{5}$ \\
$i-\mathrm{Pr}$ & $\mathrm{H}$ & $\mathbf{d}$ & $67^{12,13}$ & $p-\mathrm{MeC}_{6} \mathrm{H}_{4}$ & $p-\mathrm{MeC}_{6} \mathrm{H}_{4}$ & $\mathbf{o}$ & $93^{5}$ \\
$i-\mathrm{Bu}$ & $\mathrm{H}$ & $\mathbf{e}$ & $84^{12}$ & $\mathrm{CH}_{2} \mathrm{NMe}_{2}$ & $\mathrm{H}$ & $\mathbf{p}$ & $20^{15}$ \\
$\mathrm{Me}$ & $\mathrm{Me}$ & $\mathbf{f}$ & $94^{5}$ & $\mathrm{CH}_{2} \mathrm{Ac}^{5}$ & $\mathrm{H}$ & $\mathbf{q}$ & $13^{5}$ \\
$\mathrm{Et}$ & $\mathrm{Me}$ & $\mathbf{g}$ & $74^{5}$ & $\left(\mathrm{CH}_{2}\right)_{4} \mathrm{CH}_{3}$ & $\left(\mathrm{CH}_{2}\right)_{9} \mathrm{CO}_{2} \mathrm{H}$ & $\mathbf{r}$ & $61^{16}$ \\
$\mathrm{Et}$ & $\mathrm{Et}$ & $\mathbf{h}$ & $77^{5}$ & $p-\mathrm{ClC}_{6} \mathrm{H}_{3} \mathrm{~S}$ & $\mathrm{H}$ & $\mathbf{s}$ & $70^{17}$ \\
$-\left(\mathrm{CH}_{2}\right)_{6}{ }^{-}$ & $\mathbf{i}$ & $59^{5}$ & $o-\mathrm{BrC}_{6} \mathrm{H}_{3} \mathrm{O}$ & $\mathrm{H}$ & $\mathbf{t}$ & $72^{18}$ \\
$-\left(\mathrm{CH}_{2}\right)_{12^{-}}$ & $\mathbf{j}$ & $71^{5}$ & $\mathrm{CO}_{2} \mathrm{H}^{2}$ & $\mathrm{H}$ & $\mathbf{u}$ & $90^{5}$ \\
$\mathrm{Ph}$ & $\mathrm{H}$ & $\mathbf{k}$ & $88^{12}$ & $\mathrm{CO}_{2} \mathrm{H}$ & $\mathrm{CO}_{2} \mathrm{H}$ & $\mathbf{v}$ & $90^{5}$ \\
\hline
\end{tabular}

${ }^{\mathrm{a}}$ Labeled with ${ }^{13} \mathrm{C}$ isotope.

${ }^{\mathrm{b}} \beta$-Keto esters $\left(\mathbf{4 u}, \mathrm{R}^{1}=\mathrm{CO}_{2} \mathrm{Et}, \mathrm{R}^{2}=\mathrm{H}\right)$ and $\left(\mathbf{4 v}, \mathrm{R}^{1}=\mathrm{R}^{2}=\mathrm{CO}_{2} \mathrm{Et}\right)$ are used as substrates.

On the other hand, NMA-Na has been most frequently used for the syntheses of 4-nitrophenols (5) by the condensation with various kinds of ketones (4) (Table 1). The present method is advantageous with regard to easy modification of substituents, which dissolves several problems encountered in the Friedel-Crafts reaction. Monoalkylated nitrophenols (5a-e) are easily prepared by using methyl ketones (4a-e); worth to 
note is that isopentyl methyl ketone (4e) also usable to afford isobutyl-substituted product (5e). 2,6-Dialkyl derivatives $(\mathbf{5 f}-\mathbf{h})$ are also prepared upon treatment of NMA-Na with aliphatic ketones having longer alkyl chains (4f-h), and it is possible to link between the 2- and 6-positions when cyclic ketones $(\mathbf{4 i} \mathbf{- j})$ are employed. Benzyl ketones (4k-l) and dibenzyl ketones (4m-0) are useful substrates for the direct introduction of aryl group(s) at the position(s) adjacent to the hydroxy group. The preparation of nitrophenols (5p-t) having a functional group or a heteroatom between two aromatic rings is also achieved similarly. Although acetoacetate $(\mathbf{4 u})$ and acetonedicarboxylate (4v) efficiently undergoes the condensation with NMA-Na, the hydrolysis of the ester function(s) also proceeds because the reactions are carried out under alkaline conditions. By applying this method, nitrophenols with diverse substituents are available, which are further used for developing functional materials.

The present reaction is applied to the syntheses of polyfunctionalized compounds such as picric acid (5w) (the yield is not given), macrocyclic compounds (5x-y), quinones (6z-aa), and pyridinium $N$-phenoxide (the Reichard's-type) betaine dyes (7bb-cc). The condensation of NMA-Na with $\alpha, \alpha$ '-dinitroacetone furnishes $\mathbf{5 w}$, which is an environmentally friendly method, compared with the trinitration of phenol (Scheme 3). ${ }^{19}$ A nitrophenol framework can be incorporated upon treatment of macrocyclic ketones with NMA-Na (Figure 1). ${ }^{20}$ Nitrophenols are reduced by hydrogenation to afford aminophenols, which are transformed to quinones (6z-aa) by oxidation, ${ }^{21}$ and also transformed to pyridinium $N$-phenoxide betaine dyes (7) as a result of reaction with 2,4,6-triphenylpyririum salt (Scheme 4). ${ }^{22}$

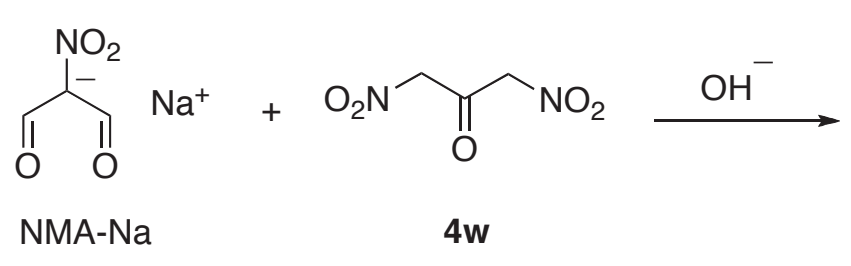<smiles>O=[N+]([O-])c1cc([N+](=O)[O-])c(O)c([N+](=O)[O-])c1</smiles>

\section{$5 w$}

Scheme 3. Synthesis of picric acid (5w) using NMA-Na

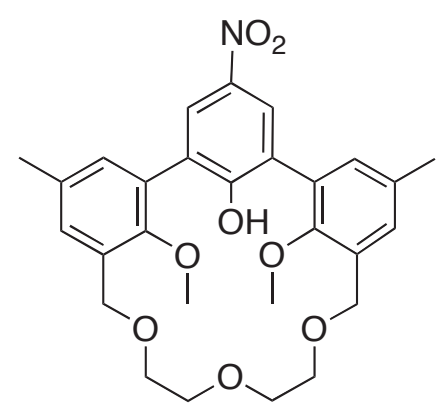

$5 \times 89 \%$

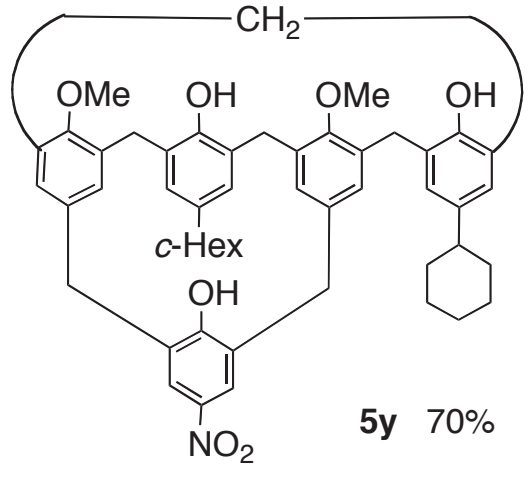

5y $70 \%$

Figure 1. Macrocyclic nitrophenols (5x) and (5y) 
<smiles>COc1c(Br)cc(C)cc1-c1cc([N+](=O)[O-])cc(-c2cc(C)cc(Br)c2OC)c1O</smiles><smiles></smiles>

$5 z$

$6 z 75 \%$

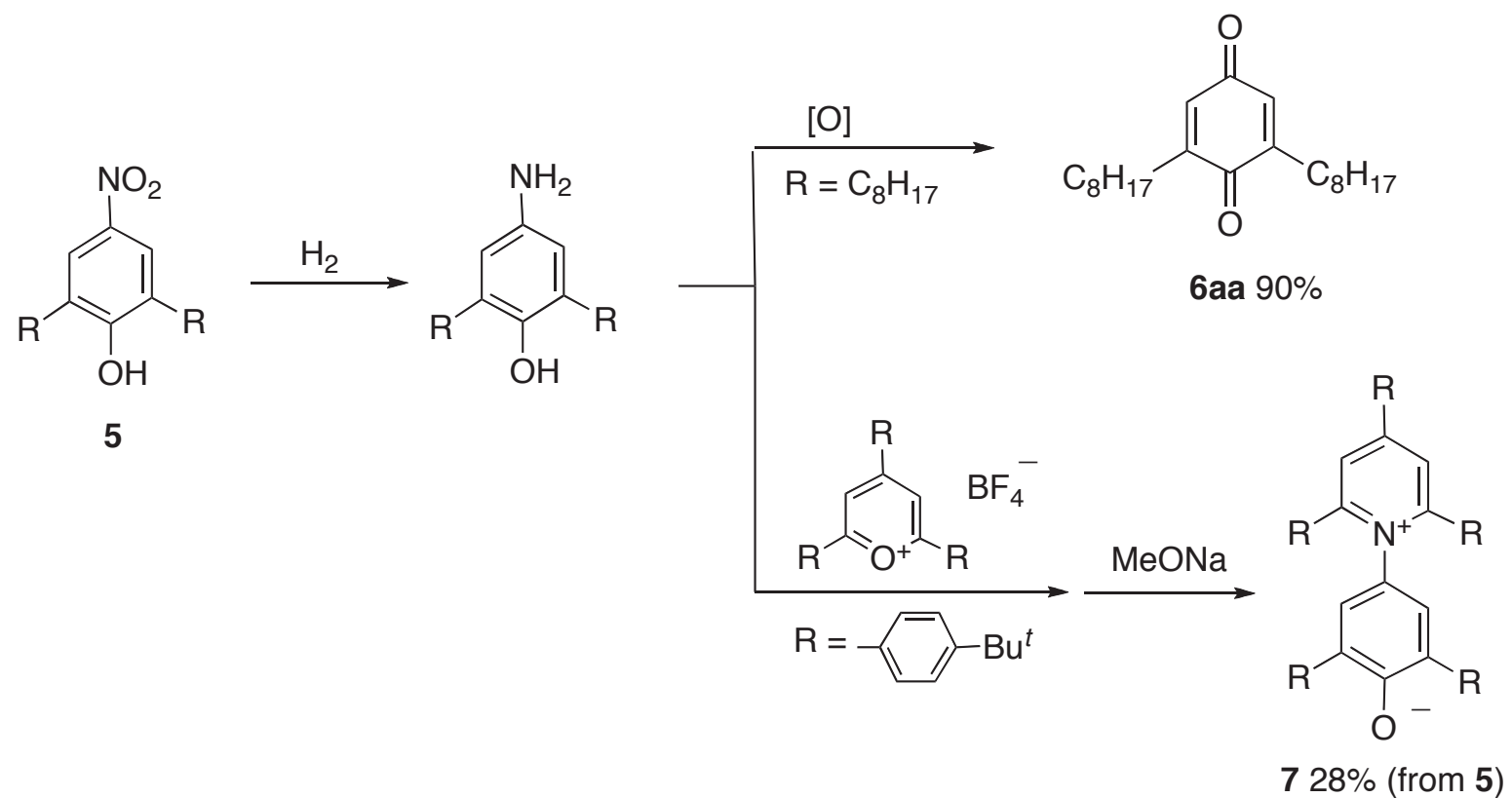

Scheme 4. Chemical transformations of 2,6-disubstituted nitrophenols

\section{1-3. Syntheses of 3-nitropyridines}

NMA-Na condenses with cyanoacetamide in the presence of benzyltrimethylammonium hydroxide (Triton B) to give 3-cyano-5-nitro-2-pyridone (8) efficiently (Scheme 5). ${ }^{23}$ Recently, it was reported that acetylated NMA-Na reacts with $\beta$-functionalized enamines $(\mathbf{9})$ to afford functionalized nitropyridines (10) (Scheme 6), which are not available by the direct nitration of the corresponding pyridine derivatives. ${ }^{24}$<smiles>N#CCC(N)=O</smiles>
NMA-Na<smiles>N#Cc1cc([N+](=O)[O-])c[nH]c1=O</smiles>

8

Scheme 5. Condensation of NMA-Na with cyanoacetamide leading to 8 


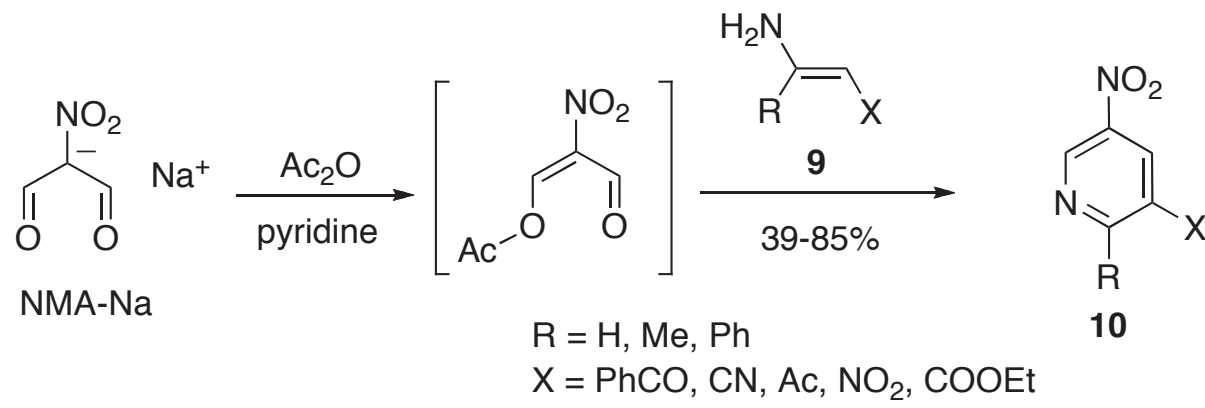

Scheme 6. Syntheses of functionalized nitropyridines (10)

\section{1-4. Syntheses of nitropyrimidines and their condensed derivatives}

Amidines are usable as dinucleophiles to be condensed with NMA-Na, of which two nucleophilic nitrogen atoms are incorporated in a ring to afford pyrimidine frameworks. ${ }^{5}$ Since Fanta and Hedman reported the synthesis of 5-nitropyrimidines, ${ }^{25}$ this procedure is still one of important protocols even now for the preparation of functionalized pyrimidines, which often reveal biological activities. ${ }^{26}$ Furthermore, van der Plas et al. showed 5-nitropyrimidine (11) serves as a good precursor for the synthesis of annelated pyridine (12) by the intramolecular ring transformation (Scheme 7) ${ }^{27}$ It is possible to use aminoazoles (13) as the dinucleophiles, which affords fused pyrimidines, 6-nitrotriazolo[1,5- $a$ ]pyrimidines (14) (Scheme 8). ${ }^{28}$

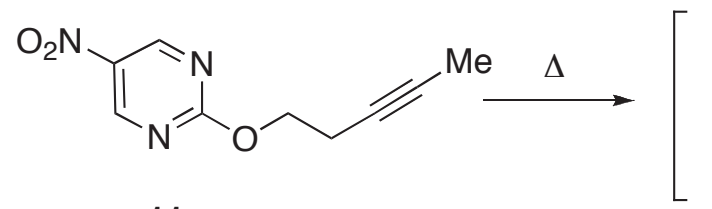

11

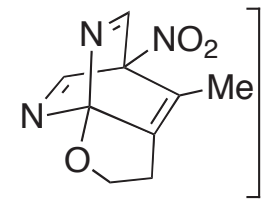

$83 \%$<smiles>Cc1c([N+](=O)[O-])cnc2c1CCO2</smiles>

12

Scheme 7. Ring transformation of nitropyrmidine (11)<smiles>[R]c1n[nH]c(N)n1</smiles>

Scheme 8. Condensation of NMA-Na with aminotriazole (13) leading to 14 


\section{1-5. The Skraup reaction using NMA-Na}

The Skraup reaction is a fundamental procedure for the synthesis of quinoline derivatives, in which an aniline derivative condenses with acrolein to construct a fused pyridine ring. In this procedure, other combinations of (hetero)aromatic amines, and NMA-Na are also usable, leading to polycyclic systems having a nitro group. For example, when naphtylamine is condensed with NMA-Na, 3-nitrobenzo[h]quinoline (16) is formed via an imine intermediate (15), which can be transformed to naphto[1,5]naphthyridine (17) (Scheme 9) ${ }^{29}$ It is also possible to construct a pyridine ring on an indole ring. ${ }^{30}$

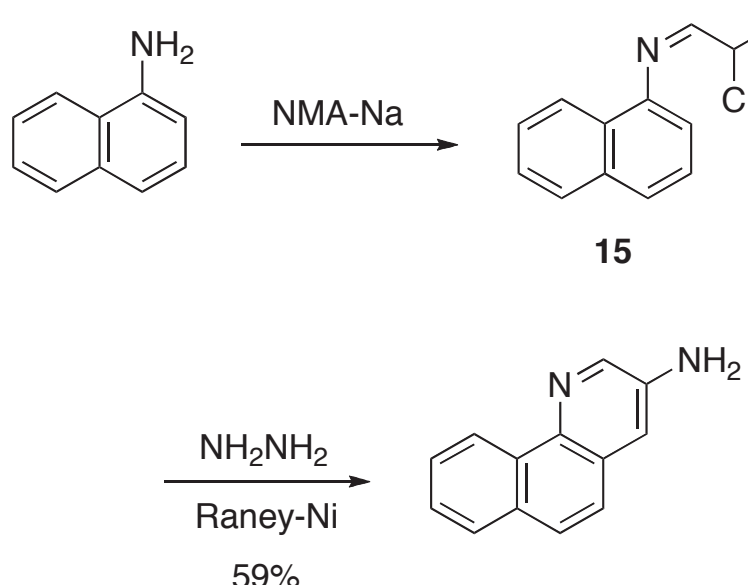

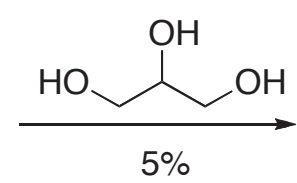

$59 \%$<smiles>O=[N+]([O-])c1cnc2c(ccc3ccccc32)c1</smiles>

16<smiles>c1ccc2nc3ccccc3cc2c1</smiles>

17

Scheme 9. A synthetic route for naphthonaphthyridine (17) using the Skraup reaction

The Skraup reaction similarly proceeds even when $\pi$-sufficient heteroaromatic amines are employed as substrates. Amino-substituted thiophenes, pyrroles, and pyrazoles (18) serve as the substrates to undergo the condensation with NMA-Na, affording the corresponding thienopyridines, pyrrolopyridines, and pyrazolopyridines (19), respectively (Scheme 10). ${ }^{31}$ On the other hand, $\pi$-deficient heterocyclic amines hardly undergo the condensation with NMA-Na. However, the condensation proceeds, when the substrate has an electron-donating group, such as a hydroxy or amino group. Indeed, pyrido[2,3- $d$ ]pyrimidine (21) is readily prepared upon treatment of triaminopyrimidine (20) with NMA-Na under acidic conditions (Scheme 11). ${ }^{32}$

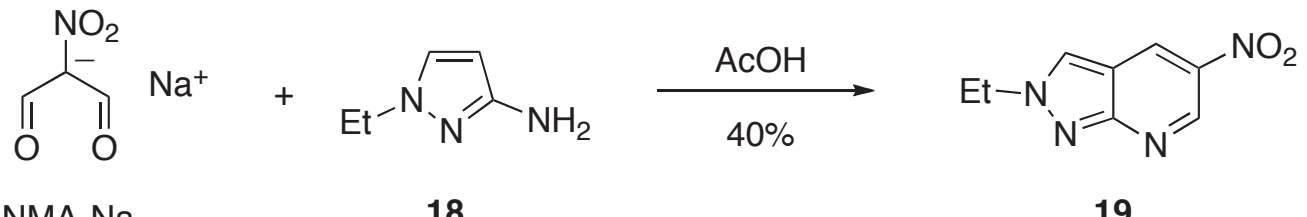


<smiles>O=CC(C=O)[N+](=O)[O-]</smiles>

NMA-Na<smiles>Nc1cc(N)nc(N)n1</smiles>

20

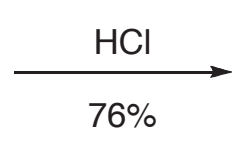<smiles>CCc1cc([N+](=O)[O-])cnc1N=C(C)N</smiles>

21

Scheme 11. Synthesis of pyrido[2,3-d]pyrimidine (21)

\section{1-6. Syntheses of other ring systems}

NMA-Na can be also used for the construction of other ring systems such as 1-substituted 4-nitropyrazoles (22), ${ }^{33}$ 4-nitropyrrole-2-carboxylate $(\mathbf{2 3})^{34}$ and 1,4,8,11-tetraaza[14]annulene derivatives (24) ${ }^{35}$ by the condensation with hydrazines (Table 2), glycine ester and 1,2-diaminobenzenes, respectively (Scheme 12).

Table 2. Condensation of NMA-Na with hydrazines leading to nitropyrazoles 22.

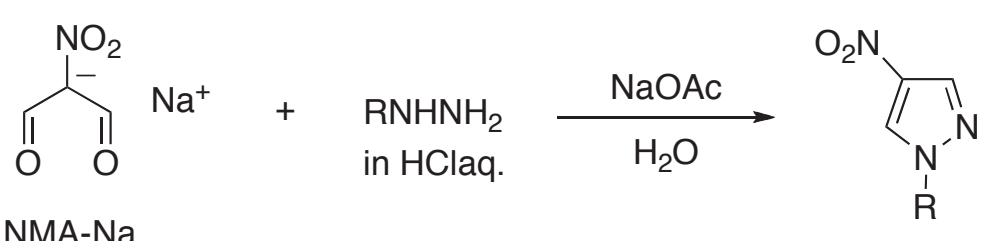

\begin{tabular}{cccccc}
\hline $\mathrm{R}$ & & yield/\% & $\mathrm{R}$ & & yield/\% \\
\hline $\mathrm{PhCH}_{2}$ & a & 76 & 2-pyridyl & d & 31 \\
$\mathrm{PhCH}_{2} \mathrm{CH}_{2}$ & b & 67 & 3-pyridyl & e & 49 \\
2-benzothiazolyl & c & 64 & 4-pyridyl & $\mathbf{f}$ & 48 \\
\hline
\end{tabular}<smiles>CCOC(=O)CN(C)O[Na]</smiles>
NMA-Na<smiles>O=CC(C=O)[N+](=O)[O-]</smiles><smiles>[R]c1cccc(N)c1N</smiles><smiles>CCOC(=O)c1cc([N+](=O)[O-])c[nH]1</smiles>

23<smiles>[R]c1cccc(N/C=C(/C=N/c2ccccc2N/C=C(/C=N/c2ccccc2)[N+](=O)[O-])[N+](=O)[O-])c1</smiles>

Scheme 12. Other condensation of NMA-Na 
When NMA-Na is subjected to the reaction with diazonium salts (25) derived from aminotriazoles, the Japp-Klingemann reaction proceeds to afford triazolo[5,1-c][1,2,4]triazines (26) (Scheme 13). ${ }^{36}$<smiles>[R]c1n[nH]c([N+]#N)n1</smiles>

25

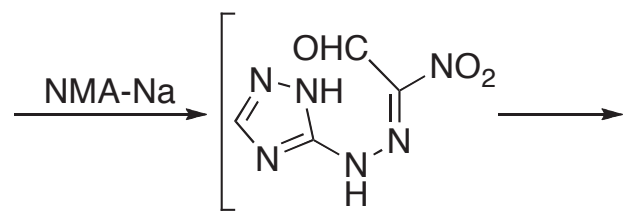<smiles>[R]c1nc2nnc(CCCCO)cn2n1</smiles><smiles>[R]c1nc2n(n1)C(O)C([N+](=O)[O-])=NN2</smiles>

26

Scheme 13. The Japp-Klingemann reaction using NMA-Na

\section{1-7. Limitation of NMA-Na and other synthetic equivalents of NMA-H}

As mentioned so far, NMA-Na has been widely employed as the useful synthetic equivalent of NMA-H, and its synthetic value is still high even now. However, this reagent suffers from the following drawbacks. In addition to some problems mentioned in Section 1-1, it is claimed that crude NMA-Na is impact-sensitive and thermally unstable, and should be handled as a potentially explosive material. ${ }^{5,6}$ Furthermore, the reactions of NMA-Na require to use water and/or ethanol as the solvent because of its low solubility to common organic solvents. Despite these drawbacks, NMA-Na has been employed as the synthetic equivalent of NMA-H.

Recently, several other synthetic equivalents have been developed to overcome these disadvantages of NMA-Na, 1-methyl-3,5-dinitro-2-pyridone (DNP), 1-methyl-5-nitro-2-pyrimidinone (NPM), 4-amino-3-nitro-1-azadienamines (ANADs), $\beta$-formyl- $\beta$-nitroenamines (FNEs), and 1,4-dinitropyrazole (NPZ) (Figure 2). In the following chapters, chemistry of these synthetic equivalents is reviewed.<smiles>Cn1cc([N+](=O)[O-])cc([N+](=O)[O-])c1=O</smiles>

DNP<smiles>Cn1cc([N+](=O)[O-])cnc1=O</smiles>

NPM<smiles>[R]N/C=C(/C=N/P)[N+](=O)[O-]</smiles>

ANAD<smiles>[R]N/C=C(/C=O)[N+](=O)[O-]</smiles>

FNE<smiles>O=[N+]([O-])c1cnn([N+](=O)[O-])c1</smiles>

NPZ

Figure 2. Synthetic equivalents of NMA-H 


\section{1-METHYL-3,5-DINITRO-2-PYRIDONE (DNP) AND}

\section{1-METHYL-5-NITRO-2-PYRIMIDINONE (NPM)}

\section{2-1. Preparative methods for DNP and NPM}

When 1-methylpyridinium salt (27) is oxidized under alkaline conditions, 1-methyl-2-pyridone (28) is formed. ${ }^{37}$ On the other hand, 1-methyl-2-pyrimidinone (29) is prepared by the condensation of $N$-methylurea with 1,1,3,3-tetramethoxypropane. ${ }^{38}$ Because somewhat aromaticity is still remained for these products (28) and (29) owing to their resonance structure, nitration easily proceeds under mild conditions to afford DNP and NPM, respectively (Scheme 14).
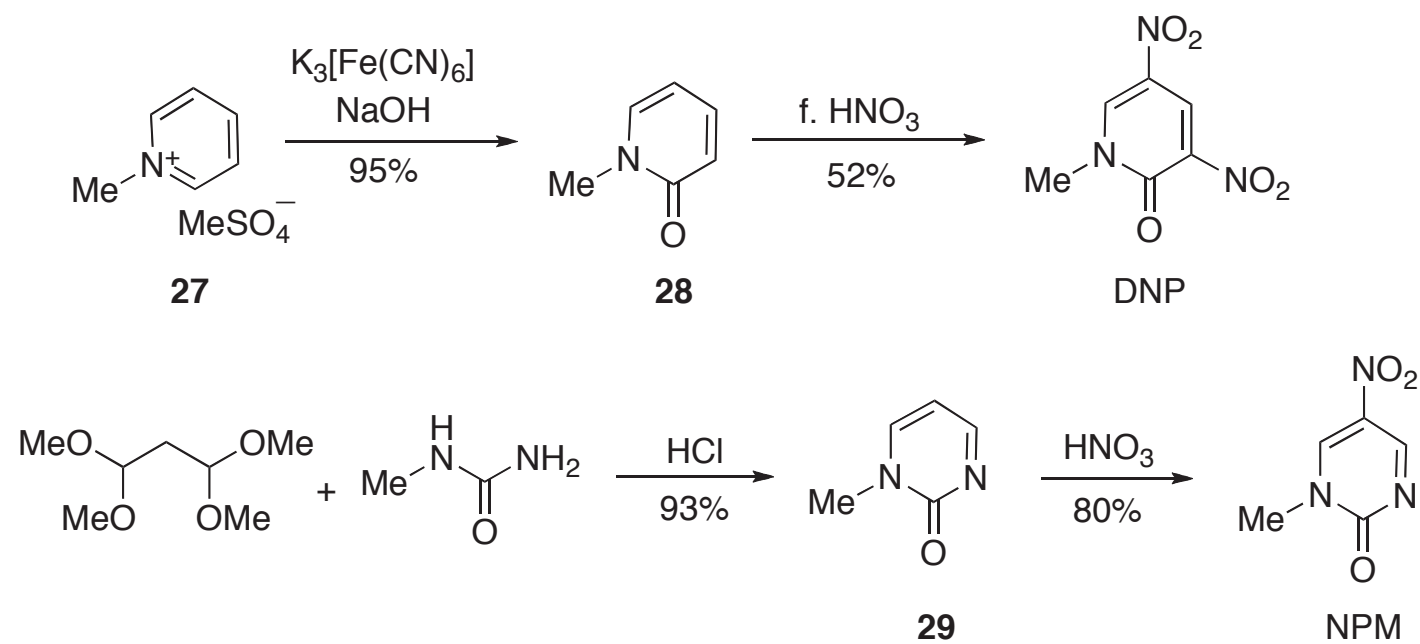

Scheme 14. Preparative methods for DNP and NPM

\section{2-2. Ring transformation of DNP}

The electron-density of DNP is considerably diminished by two nitro groups, a carbonyl group and a ring nitrogen. Moreover, DNP has a good leaving group as a partial structure; a nitroacetamide framework easily eliminates as a stable anion. These structural features enable a nucleophilic ring transformation. Indeed, DNP undergoes the ring transformation with sodium enolates of 1,3-dicarbonyl compounds to afford difunctionalized 4-nitrophenols (5u-v), in which DNP serves as the safer synthetic equivalent of NMA-H (Scheme 15). ${ }^{39}$ As mentioned in Section 1-2, when NMA-Na is subjected to condensation with $\beta$-keto esters $(\mathbf{4 u}-\mathbf{v})$, the hydrolysis of the ester function also occurs to give $\mathbf{5} \mathbf{u}^{\prime} \mathbf{- v} \mathbf{v}^{\prime}$. Contrary to this, an ester function tolerates under conditions used for the ring transformation because aprotic solvent is usable. In the present ring transformation, the introduction of an acyl group is also possible by using sodium enolates of acetylacetone and acetopyruvate. 
<smiles></smiles>

DNP

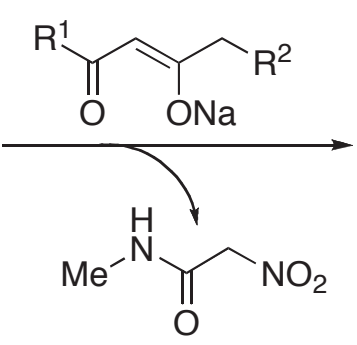<smiles>[R]C(=O)c1cc([N+](=O)[O-])cc([R])c1O</smiles>

\begin{tabular}{cccc}
\hline $\mathrm{R}^{1}$ & $\mathrm{R}^{2}$ & & yield/\% \\
\hline $\mathrm{OEt}$ & $\mathrm{H}$ & $\mathbf{5 u}$ & 61 \\
$\mathrm{OEt}$ & $\mathrm{CO}_{2} \mathrm{Et}$ & $\mathbf{5 v}$ & 91 \\
$\mathrm{Me}$ & $\mathrm{H}$ & $\mathbf{5 b b}$ & 53 \\
$\mathrm{CO}_{2} \mathrm{Et}$ & $\mathrm{H}$ & $\mathbf{5 c c}$ & 42
\end{tabular}

Scheme 15. Ringtransformation of DNP leading to functionalized nitrophenols<smiles>Cn1cc([N+](=O)[O-])cc([N+](=O)[O-])c1=O</smiles>

DNP<smiles>Cn1cc([N+](=O)[O-])cc([N+](=O)[O-])c1=O</smiles>

DNP

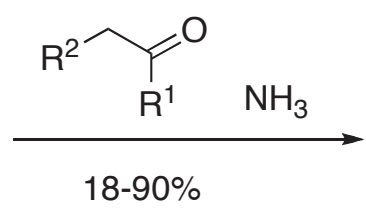<smiles>[R]c1cc([N+](=O)[O-])cnc1[R]</smiles>

30

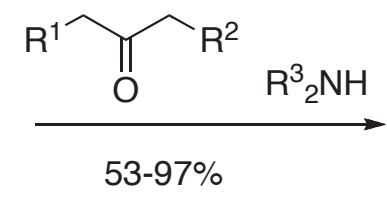

$53-97 \%$<smiles>[R]c1cc([N+](=O)[O-])cc([R])c1NP</smiles>

31
$\mathrm{R}^{1}=$ Alkyl, Aryl, Hetaryl $\mathrm{R}^{2}=\mathrm{H}$, Alkyl

$\mathrm{R}^{1}, \mathrm{R}^{2}=\mathrm{H}, \mathrm{Me}, \mathrm{CO}_{2} \mathrm{Et}$ $\mathrm{R}^{3}=\mathrm{Et},-\left(\mathrm{CH}_{2}\right)_{4}$ $\mathrm{R}^{2}=\mathrm{H}$, Alkyl

Scheme 16. Three components ring transformation of DNP

Simple ketones can be employed as the substrates for the ring transformation when a nitrogen source is additionally present, namely, a three-component ring transformation can proceed. ${ }^{40}$ 5,6-Disubstituted 3-nitropyridines (30) are synthesized upon treatment of DNP with ketones in the presence of ammonia. ${ }^{41}$ Furthermore, 2,6-disubstituted 4-nitroanilines (31) are formed when DNP is allowed to react with ketones in the presence of amines (Scheme 16). ${ }^{42}$ Ammonium acetate is also usable as the nitrogen source instead of ammonia, which enables the ring transformation under mild conditions. ${ }^{43}$ This reactivity of DNP is synthetically useful because same products $(\mathbf{3 0})$ and $(\mathbf{3 1})$ are not available from NMA-Na.

\section{2-3. Ring transformation of NPM}

NPM, an azaanalog of DNP, undergoes a three-component ring transformation similarly upon treatment with ketones in the presence of ammonia to afford nitropyridines (30) (Scheme 17). ${ }^{44}$ However, the 
reactivity of NPM is lower than that of DNP besides the limited scope of the substrates, because the partial structure of NPM should leave as an unstable anion of $N$-methylurea during the ring transformation. The low leaving ability of methylurea prevents the ring transformation in the reaction of NPM with the enolate anion of diethyl acetonedicarboxylate, in which diazabicyclo[3.3.1]nonane (32) is isolated instead of the corresponding nitrophenols (5) (Scheme 18). ${ }^{44}$<smiles>Cn1cc([N+](=O)[O-])cnc1=O</smiles>

NPM
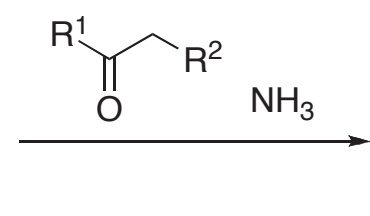<smiles>[R]c1cc([N+](=O)[O-])cnc1[R]</smiles>

30

\begin{tabular}{|c|c|}
\hline $\mathrm{R}^{1} \quad \mathrm{R}^{2}$ & yield $/ \%$ \\
\hline$-\left(\mathrm{CH}_{2}\right)_{4^{-}}$ & 33 \\
\hline
\end{tabular}

$\begin{array}{lll}\mathrm{Me} & \mathrm{H} & 43\end{array}$

$\mathrm{H} \quad \mathrm{Me} \quad 58$

Scheme 17. Three components ring transformation of NPM<smiles>Cn1cc([N+](=O)[O-])cnc1=O</smiles>

NPM

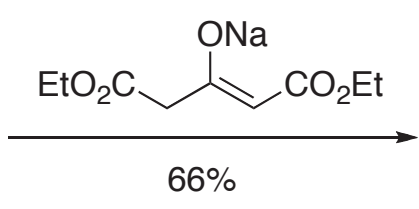

$\mathrm{EtO}_{2} \mathrm{C}$<smiles>CCOC(=O)C1=C(O)C(C(=O)OCC)C2C([N+](=O)[O-])C1NC(=O)N2C</smiles>

32

Scheme 18. Synthesis of diazabicyclic compound (32)

\section{4-AMINO-3-NITRO-1-AZADIENAMINES (ANADs) AND $\beta$-FORMYL- $\beta$-NITROENAMINEs (FNEs)}

\section{3-1. Preparation and property of ANADs}

Both DNP and NPM are highly electron-deficient to cause aminolysis. When DNP is allowed to react with an amine in pyridine, aminolysis occurs to afford ANAD together with $\mathbf{3 3}$, which is an adduct of DNP with anionic nitroacetamide liberated during the formation of ANAD.${ }^{45}$ Hence, a half amount of DNP is consumed by the undesired side-reaction (Scheme 19). On the other hand, the higher solubility of NPM enables a similar aminolysis in methanol leading to ANAD (Scheme 19). ${ }^{46}$ In the present reaction, less nucleophilic aromatic amines are applicable to afford ANADs ( $\mathrm{R}=$ aromatic ring), which is used as unique $\beta$-diketiminate ligands. ${ }^{47,48}$ In the ${ }^{1} \mathrm{H}$ NMR, two vinylic protons of ANAD are equivalently observed because ANAD tautmerizes faster than the time-scale for the NMR measurement (Scheme 20). ${ }^{48}$ ANAD serves as a synthetic equivalent of NMA-H to afford nitropyrazole (22g) in good yield by the reaction with methylhydrazine (Scheme 20$){ }^{46}$ 
<smiles>Cn1cc([N+](=O)[O-])cc([N+](=O)[O-])c1=O</smiles><smiles>Cn1cc([N+](=O)[O-])cnc1=O</smiles>

NPM
$\underset{\mathrm{MeOH}}{\stackrel{\mathrm{BuNH}}{2}}$

$\mathrm{R}^{-\mathrm{N}}$<smiles>[R]N/C=C(/C=N/P)[N+](=O)[O-]</smiles>

ANAD

Scheme 19. Aminolysis of DNP and NPM leading to ANADs<smiles>CCCN/C=C(\C=N\CC)[N+](=O)[O-]</smiles><smiles>C=C</smiles>

ANAD<smiles>CCC/N=C/C(=C/NCCC)[N+](=O)[O-]</smiles><smiles>CN(N)O</smiles>

Scheme 20. Tautomerism of ANAD

\section{3-2. Preparation of FNEs}

When ANADs are charged on silica gel for a few days at room temperature, half hydrolysis efficiently occurs to afford FNEs as a mixture of $E / Z$ isomers in a ratio of about 3/1 (Scheme 21). ${ }^{46}$ FNEs are one class of typical push-pull alkenes possessing biased electron density, which exhibit versatile reactivity. The formyl group and the $\alpha$-carbon are electrophilic sites, and the amino group and the $\beta$-carbon are nucleophilic sites (Figure 3). In the reaction with a dinucleophile, FNEs serve as dielectrophiles to give nitro compounds; it means that FNE is a synthetic equivalent of NMA-H. On the other hand, FNE also serves as a building block possessing both a nucleophilic group and an electrophilic moiety. Indeed, 3-ethoxycarbonyl-5-nitro-2-pyrione is readily prepared upon treatment of FNE with diethyl malonate, and 2-alkylamino-3-ethoxycarbonyl-5-nitropyridine is formed via the Dimroth rearrangement by the reaction with ethyl cyanoacetate. ${ }^{49}$ The present method is useful for developing functional materials, because products also have a push-pull property. 
<smiles>[R]/N=C/C(=C\N[R])[N+](=O)[O-]</smiles>

Scheme 21. Half hydrolysis of ANADs affording FNEs

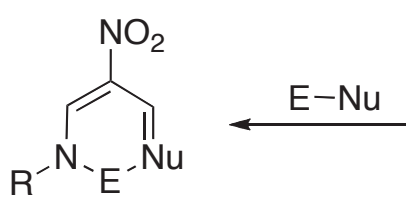

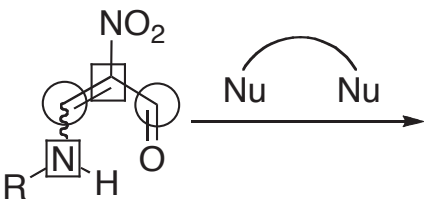<smiles>O=[N+]([O-])C1=CNCCC=N1</smiles>

Electrophilic site

FNE

Figure 3. Different reactivities of FNE

\section{3-3. Syntheses of 6-membered and 7-membered nitro compounds}

FNE reacts with ketones (4) to undergo a double condensation affording 2,6-disubstituted 4-nitrophenols (5) (Table 3). ${ }^{50}$ FNE does not show an explosive property and is highly soluble into organic solvents. These features are advantageous for practical use, compared with NMA-Na (see Section 1-1), with regard to safety and treatability. When guanidines (34) are employed as the dinucleophiles, pyrimidines (35) are formed (Scheme 22). ${ }^{51}$

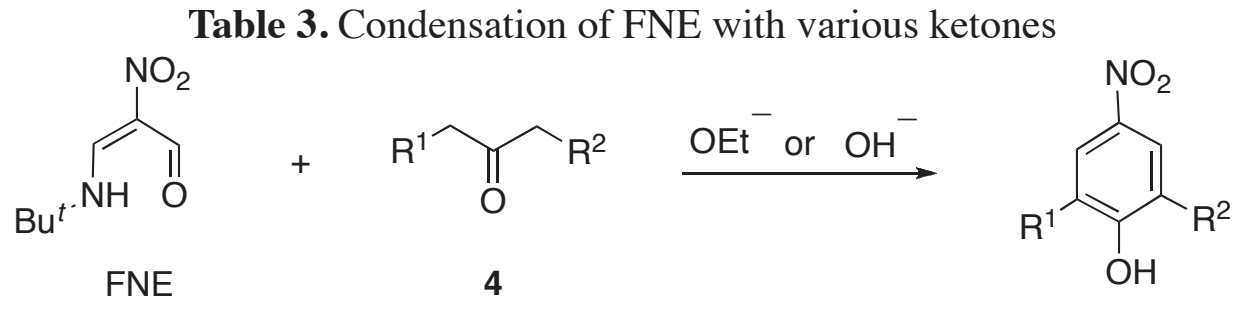

5

\begin{tabular}{cccccccc}
\hline $\mathrm{R}^{1}$ & $\mathrm{R}^{2}$ & & yield/\% & $\mathrm{R}^{1}$ & $\mathrm{R}^{2}$ & & yield/\% \\
\hline$i-\mathrm{Pr}$ & $\mathrm{H}$ & d & quant. & $i-\mathrm{Pr}$ & $i-\mathrm{Pr}$ & $\mathbf{g g}$ & 12 \\
$\mathrm{Et}$ & $\mathrm{Me}$ & $\mathbf{g}$ & 74 & $\mathrm{Ph}$ & $\mathrm{Pr}$ & $\mathbf{h h}$ & 76 \\
$\mathrm{Ph}$ & $\mathrm{Ph}$ & $\mathbf{n}$ & 77 & $\mathrm{CO}_{2} \mathrm{Et}$ & $\mathrm{H}$ & $\mathbf{u}$ & 55 \\
$\mathrm{Pr}$ & $\mathrm{H}$ & ee & quant. & $\mathrm{CO}_{2} \mathrm{Et}$ & $\mathrm{CO}_{2} \mathrm{Et}$ & $\mathbf{v}$ & 80 \\
$\mathrm{Pr}$ & $\mathrm{Pr}$ & ff & quant. & $\mathrm{CO}_{2} \mathrm{Me}$ & $\mathrm{OMe}$ & ii & 51 \\
\hline
\end{tabular}


<smiles>CCn1cc([N+](=O)[O-])cnc1=N</smiles>

Scheme 22. Synthesis of nitropyrimidine derivatives (35)

Table 4. Condensation of FNE with 1,2-diamines (36) leading to diazepines (37)<smiles>CC(C)(C)N/C=C(/C=O)N=O</smiles>

FNE<smiles>[R]C(N)C([R])N</smiles>

36<smiles>[R7]C1N=CC([N+](=O)[O-])=CN([R7])C1[R]</smiles>

37

\begin{tabular}{clccc}
\hline $\mathrm{R}^{1}$ & $\mathrm{R}^{2}$ & $\mathrm{R}^{3}$ & & yield/\% \\
\hline $\mathrm{H}$ & $\mathrm{H}$ & $\mathrm{H}$ & $\mathbf{a}$ & quant. \\
$\mathrm{Et}$ & $\mathrm{H}$ & $\mathrm{H}$ & $\mathbf{b}$ & 80 \\
$\mathrm{H}$ & $\mathrm{Me}$ & $\mathrm{H}$ & $\mathbf{c}$ & 69 \\
$\mathrm{H}$ & $-\left(\mathrm{CH}_{2}\right)_{4^{-}}$ & $($cis $)$ & $\mathbf{d}$ & 79 \\
$\mathrm{H}$ & $-\left(\mathrm{CH}_{2}\right)_{4^{-}}$ & $($trans $)$ & $\mathbf{e}$ & 86 \\
$\mathrm{H}$ & \multicolumn{2}{c}{ o-phenylene } & $\mathbf{f}$ & 0 \\
\hline
\end{tabular}

6-Nitro-1,4-diazepines (37) are prepared upon treatment of FNE with 1,2-diamines (36) (Table 3). ${ }^{51,52}$ $N$-Substituted and 2,3-disubstituted diamines (36b and 36c-e) are usable as the substrates to afford the corresponding diazepines (37b-e). When this reaction is conducted in a concentrated solution, oligomeric products (38) are also formed (Figure 4). In the reaction of FNE with 36f, the formation of $\mathbf{3 8 f}$ is confirmed, however, $\mathbf{3 7 f}$ is not detected, which is presumably due to the rigid structure of $\mathbf{3 6 f}$.<smiles>CC12C=NCC(C)(CNC=C([N+](=O)[O-])C=NC1)CNC2</smiles>

$38 a$

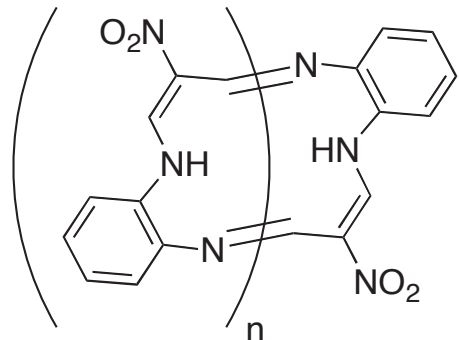

$38 f$

Figure 4. Oligomeric products (38) 


\section{3-4. Syntheses of nitroazoles}

Five membered heterocyclic compounds are also prepared using FNE. Condensation of FNE with glycine ethyl ester affords ethyl 4-nitropyrrole-2-carboxylate (23) in 59\% yield. On the other hand, nitroisoxazole (40) is not detected when FNE is treated with hydroxylamine liberated from its hydrochloride (39) in the presence of triethylamine. This problem is overcome by employing hydrochloride (39) itself as a dinucleophile to afford $\mathbf{4 0}$ even though the yield is low (Scheme 23). ${ }^{51}$ Isolated isoxazole (40) reacts with 39 under the same conditions to furnish unidentified products, and the low yield of $\mathbf{4 0}$ is also due to the competitive decomposition. On the other hand, nitropyrazoles (22) are readily prepared by the condensation of FNE with hydrazines. ${ }^{51}$ The high solubility of FNE into organic solvents enables to employ various kinds of hydrazines, which consequently leads to the synthesis of nitropyrazoles having a bulky alkyl group, a functional group, or an aromatic group at the 1-position (Table 5), which is one of advantageous features in comparison with a conventional synthetic equivalent, NMA-Na.

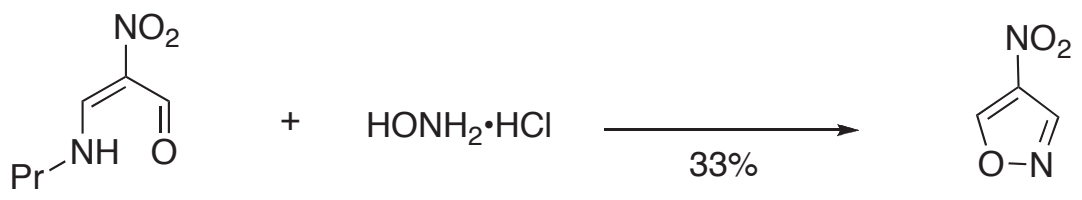

$\begin{array}{lll}\text { FNE } & 39 & 40\end{array}$

Scheme 23. Synthesis of 4-nitroisoxazole (40)

Table 5. Syntheses of nitropyrazoles (22)

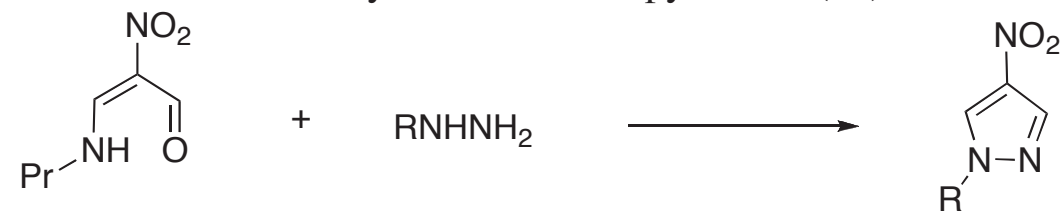

FNE $\quad 22$

\begin{tabular}{cccccc}
\hline $\mathrm{R}$ & & $\mathrm{yield} / \%$ & $\mathrm{R}$ & $\mathrm{yield} / \%$ \\
\hline $\mathrm{Me}$ & $\mathbf{g}$ & 96 & $\mathrm{CH}_{2} \mathrm{COOEt}$ & $\mathbf{j}$ & 90 \\
$\mathrm{H}$ & $\mathbf{h}$ & 87 & $\mathrm{Ph}$ & $\mathbf{k}$ & 35 \\
$t-\mathrm{Bu}$ & $\mathbf{i}$ & 59 & $p-\mathrm{MeC}_{6} \mathrm{H}_{4}$ & $\mathbf{l}$ & 47 \\
\hline
\end{tabular}

\section{1,4-DINITROPYRAZOLE (NPZ)}

NPZ prepared by the nitration of commercially available pyrazole is also stable and well soluble into organic solvents, which also serves as a synthetic equivalent of NMA-H usable in organic media. ${ }^{53}$ 4-Nitropyrazoles (22) having an aromatic group at the 1-position are prepared by the condensation of 
NPZ with aromatic hydrazines (Table 6), however only a mixture of oligo(nitropyrazoles) is obtained in the reaction with guanidines because of the high reactivity of NPZ. On the other hand, nitroisoxazole (40) is prepared in $77 \%$ yield upon treatment with hydroxylamine hydrochloride (39) in the presence of sodium methoxide.

Table 6. Syntheses of nitropyrazoles (22)

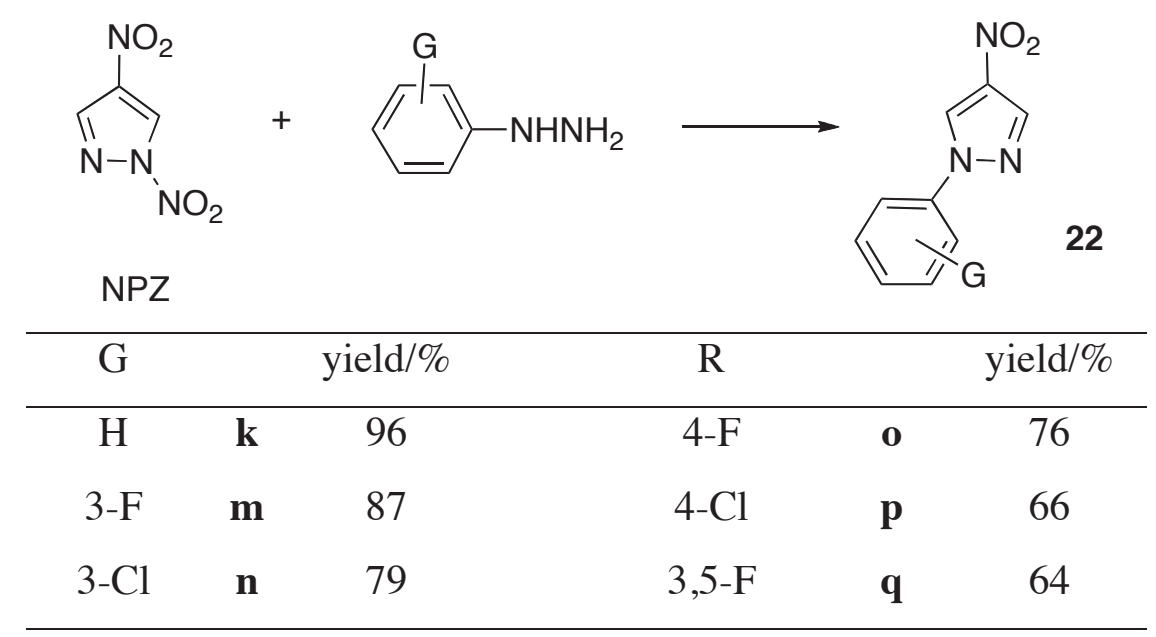

\section{SUMMARY}

Although NMA-Na has been employed from old time as an excellent synthetic equivalent of unstable NMA-H, there are some restrictions for practical use; formation of explosive by-products and insolubility into common organic solvents. From the viewpoints of safety and treatability, several other synthetic equivalents such as DNP, NPO, ANADs, FNEs, and NPZ have been developed. The recent advances of these reagents will contribute to the synthetic chemistry for nitro compounds and their derivatives.

\section{REFERENCES AND NOTES}

1. N. Ono, The Nitro Group in Organic Chemistry, Wiley, New York, (2001); H. Feuer and A. T. Nielsen, Nitro Compounds, Wiley, New York (1990).

2. N. Zarycz, G. A. Aucar, and C. O. Della Védova, J. Phys. Chem. A, 2010, 114, 7162; S. F. Tayyari, M. Zahedi-Tabrizi, H. Azizi-Toupkanloo, S. S. Hepperle, and Y. A. Wang, Chem. Phys., 2010, 368, 62; M. Palusiak, S. Simon, and M. Solà, Chem. Phys., 2007, 342, 43; W. Caminati, J. Chem. Soc., Faraday Trans. 2, 1982, 78, 825.

3. S. F. Tayyari, Z. Moosavi-Tekyeh, M. Zahedi-Tabrizi, H. Eshghi, J. S. Emampour, H. Rahemi, and M. Hassanpour, J. Mol. Struct., 2006, 782, 191. This literature affords the ${ }^{1} \mathrm{H}$ NMR of NMA-H as 
follows: ${ }^{1} \mathrm{H}$ NMR $\left(\mathrm{CDCl}_{3}\right) \delta 9.5(\mathrm{~s}, 1 \mathrm{H}, \mathrm{CH})$ and $13.75(\mathrm{~s}, 1 \mathrm{H}, \mathrm{OH})$.

4. Y. Nakaike, N. Taba, S. Itoh, Y. Tobe, N. Nishiwaki, and M. Ariga, Bull. Chem. Soc. Jpn., 2007, 80, 2413; R. Ballini, G. Bosica, and D. Fiorini, Tetrahedron, 2003, 59, 1143.

5. P. E. Fanta and R. A. Stein, Chem. Rev., 1960, 60, 261.

6. P. E. Fanta, Org Synth., 1963, Coll. Vol. 4, 844.

7. C. F. H. Allen and F. W. Spangler, Org Synth., 1955, Coll. Vol. 3, 621.

8. G. A. Taylor, Org. Synth., 1963, Coll. Vol. 4, 688.

9. This is described as a Warning in Org. Synth., 1966, 46, 1004, and author's name is not shown.

10. M. Shi, S.-C. Cui, and W.-P. Yin, Eur. J. Org. Chem., 2005, 2379; H. A. Muathen, Molecules, 2003, 8, 593; R. H. Rigterink and B. Bisabri-Ershadi, US Pat., 18525 (1986).

11. T. E. Walker, C. Matheny, C. B. Storm, and H. Hayden, J. Org. Chem., 1986, 51, 1175; H. J. Shine, K. H. Park, M. L. Brownawell, and J. S. Filippo, J. Am. Chem. Soc., 1984, 106, 7077.

12. B. Blank, F. R. Pfeiffer, C. M. Greenberg, and J. F. Kerwin, J. Med. Chem., 1963, 6, 554.

13. M. P. Dilllon, A. Jahangir, A. S.-T. Lui, and R. S. Wilhelm, US Pat., 49610 (2007).

14. J. Hung and L. M. Werbel, Eur. J. Med. Chem., 1983, 18, 61.

15. E. Y. Belyaev, N. A. Dolzhenko, V. E. Zadov, and E. S. Semichenko, Russ. J. Org. Chem., 2002, 38, 158 .

16. R. A. Sein, J. Med. Chem., 1967, 10, 162.

17. S. J. Kesten, J. Johnson, and L. M. Werbel, J. Med. Chem., 1987, 30, 906.

18. C. A. Ramsden, J. Chem. Soc., Perkin Trans. 1, 1981, 2456.

19. M. C. Davis, US Pat., 7271200 (2007).

20. D. N. Reinhoudt and P. J. Dijkstra, Pure Appl. Chem., 1988, 60, 477; B. Berger, V. Böhmer, E. Paulus, A. Rodriguez, and W. Vogt, Angew. Chem., Int. Ed. Engl., 1992, 31, 96.

21. P. J. Dijkstra, J. C. O. Boerrigter, B. J. van Steen, H. J. den Hertog, and D. N. Reinhoudt, J. Chem. Soc., Chem. Commun., 1984, 1660; E. C. Armstrong, R. L. Bent, A. Loria, J. R. Thirtle, and A. Weissberger, J. Am. Chem. Soc., 1960, 82, 1928.

22. S. Kurjatschij, W. Seichter, and E. Weber, New. J. Chem., 2010, 34, 1465; C. Reinhardt and M. Eschner, Liebigs Ann. Chem., 1991, 999; C. Reinhardt and E. Harbusch-Görnert, Liebigs Ann. Chem., 1983, 721 .

23. P. E. Fanta and R. A. Stein, J. Am. Chem. Soc., 1955, 77, 1045.

24. G. P. Sagitullina, A. K. Garkushenko, E. O. Silina, and R. S. Sagtullin, Chem. Heterocycl. Compd., 2009, 45, 948 .

25. P. E. Fanta and E. A. Hedman, J. Am. Chem. Soc., 1956, 78, 1434.

26. R. D. Farn, N. G. Morgan, and C. A. Ramsden, J. Heterocycl. Chem., 2008, 45, 887; R. M. Epand 
and J. J. Lipnieks, J. Biol. Chem., 1983, 258, 203.

27. A. E. Frissen, A. T. M. Marcelis, and H. C. van der Plas, Tetrahedron, 1989, 45, 803.

28. O. N. Chupakhin, N. A. Itsikson, S. S. Bashirov, D. G. Beresnev, and G. L. Rusinov, Heterocycles, 2005, 66, 543; V. L. Rusinov, I. Y. Postovskii, A. Y. Petrov., E. O. Sidonov, and Y. A. Azev, Chem. Heterocycl. Compd., 1981, 17, 1139.

29. I. Takeuchi, Y. Hamada, and M. Hirota, Chem. Pharm. Bull., 1993, 41, 747.

30. L. G. Yudin, S. A. Yamashkin, P. B. Terent'ev, and O. A. Solov'ev, Chem. Heterocycl. Compd., 1979, 15,1113 .

31. V. L. Rusinov, A. Y. Petrov, and O. N. Chupakhin, Chem. Heterocycl. Compd., 1992, 28, 1335 ; H. Schäfer, K. Gewald, and M. Schmidt, Chem. Heterocycl. Compd., 1983, 19, 1163.

32. A. Gangjee, A. Vasudevan, S. F. Queener, and R. L. Kisliuk, J. Med. Chem., 1996, 39, 1438; T.-C. Lee and G. Salemnick, J. Org. Chem., 1975, 40, 3608; R. Bernetti, F. Mancini, and C. C. Price, J. Org. Chem., 1962, 27, 2863.

33. M. Bianchi, F. Bonacina, A. Osvald, and C. Pirola, Farmaco, Ed. Sci., 1970, 25, 592.

34. M. Lee, D. M. Coulter, and J. W. Lown, J. Org. Chem., 1988, 53, 1855.

35. C. Reichardt and W. Scheibelein, Zeit. Natur. Teil B, 1978, 33B, 1012.

36. V. L. Rusinov, T. L. Pilicheva, O. N. Chupakhin, N. A. Klyuev, and D. T. Allakhverdieva, Chem. Heterocycl. Compd., 1986, 22, 543.

37. E. A. Prill and S. M. McElvain, Org. Synth., 1943, Coll. Vol. 2, 419.

38. J. J. Fox and D. V. Praag, J. Am. Chem. Soc., 1960, 82, 486.

39. E. Matsumura, M. Ariga, and Y. Tohda, Bull. Chem. Soc. Jpn., 1979, 52, 2413.

40. N. Nishiwaki and M. Ariga, "Ring Transformation of Nitropyrimidinone Leading to Versatile Azaheterocyclic Compounds", in Top. Heterocycl. Chem., 8, 43, ed. by S. Eguchi, Springer, Berlin (2007).

41. Y. Tohda, M. Eiraku, T. Nakagawa, Y. Usami, M. Ariga, T. Kawashima, K. Tani, H. Watanabe, and Y. Mori, Bull. Chem. Soc. Jpn., 1990, 63, 2820.

42. E. Matsumura, Y. Tohda, and M. Ariga, Bull. Chem. Soc. Jpn., 1982, 55, 2174.

43. N. Nishiwaki, H. Tatsumichi, M. Tamura, and M. Ariga, Lett. Org. Chem., 2006, 3, 629.

44. N. Nishiwaki, Y. Tohda, and M. Ariga, Synthesis, 1997, 1277.

45. Y. Tohda, M. Ariga, T. Kawashima, and E. Matsumura, Bull. Chem. Soc. Jpn., 1987, 60, 201.

46. N. Nishiwaki, Y. Tohda, and M. Ariga, Bull. Chem. Soc. Jpn., 1996, 69, 1997.

47. C. Shimokawa, Y. Tachi, N. Nishiwaki, M. Ariga, and S. Itoh, Bull. Chem. Soc. Jpn., 2006, 79, 118; S. Yokota, Y. Tachi, N. Nishiwaki, M. Ariga, and S. Itoh, Inorg. Chem., 2001, 40, 5316.

48. C. Shimokawa, S. Yokota, Y. Tachi, N. Nishiwaki, M. Ariga, and S. Itoh, Inorg. Chem., 2003, 42, 
8395.

49. Y. Nakaike, D. Hayashi, N. Nishiwaki, Y. Tobe, and M. Ariga, Org. Biomol. Chem., 2009, 7, 325.

50. Y. Nakaike, Y. Kamijo, S. Mori, M. Tamura, N. Nishiwaki, and M. Ariga, J. Org. Chem., 2005, 70, 10169.

51. N. Nishiwaki, T. Ogihara, T. Takami, M. Tamura, and M. Ariga, J. Org. Chem., 2004, 69, 8382.

52. N. Nishiwaki, T. Ogihara, M. Tamura, N. Asaka, K. Hori, Y. Tohda, and M. Ariga, Heterocycles, $2002, \mathbf{5 7}, 425$.

53. R. Jędrysiak, M. Sawicki, P. Wagner, and J. Suwiński, ARKIVOC, 2007, vi, 103.

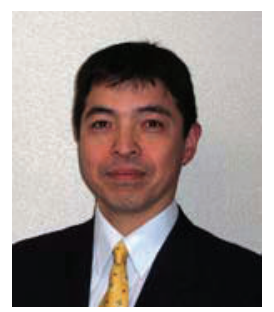

Professor Nagatoshi Nishiwaki received his Ph. D. in 1991 from Osaka University. He worked at Professor Ariga's group in Department of Chemistry, Osaka Kyoiku University, as assistant professor (1991-2000) and as associate professor (2001-2008). From 2000 to 2001, he joined to Karl Anker Jørgensen's group at Århus University in Denmark. He worked at Center for Collaborative Research, Anan National College of Technology as associate professor from 2008 to 2009. Then, he moved to School of Environmental Science and Engineering, Kochi University of Technology in 2009, and he is a professor from 2011. His research interests comprise synthetic organic chemistry using nitro compounds, heterocycles (synthesis, ring transformation, 1,3-dipolar cycloaddition, application as tools in organic synthesis), pseudo-intramolecular reaction, and solid supported palladium catalysts.

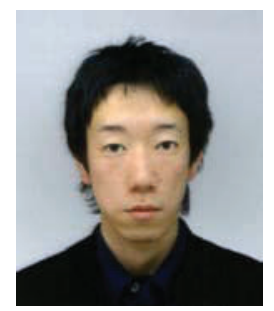

Dr. Shotaro Hirao was obtained his Ph. D. degree in 2010 from Nagasaki University. His doctoral research, under the guidance of Professor Fumito Ishibashi, focused on the synthesis of marine pyrrole alkaloids. He joined Professor Nishiwaki's group in School of Environmental Science and Engineering, Kochi University of Technology as an assistant professor in 2010. His research interest is in the area of heterocyclic chemistry and natural products chemistry.

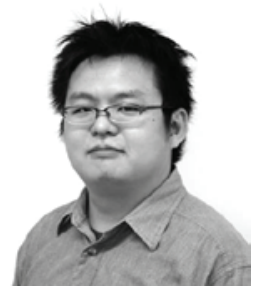

Dr. Jun Sawayama was obtained his Dr. Eng. degree in 2010 from Tokyo University with professor Koji Araki, where his thesis was focused on supramolecular chemistry based on hydrogen bonding. From 2010, he is an assistant professor of Kochi University of Technology in the group of professor Kazuhiko Saigo. Currently, his research interests in organic chemistry toward chiral recognition and asymmetric synthesis.

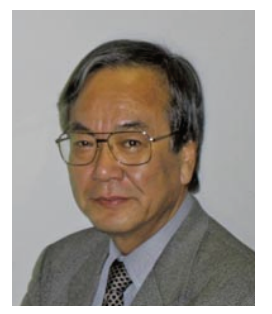

Professor Kazuhiko Saigo was obtained his Ph. D. degree in 1976 from Tokyo Institute of Technology. He was a research associate/associate professor/professor of Tokyo Institute of Technology (1972-73), The University of Tokyo (1973-76), Saitama University (1976-82), The University of Tokyo (1982-2010), and then Kochi University of Technology (2010-). From 2011, he is Vice President of KUT. 